\title{
Longitudinal sleeve gastrectomy: current perspectives
}

This article was published in the following Dove Press journal:

Open Access Surgery

14 May 2014

Number of times this article has been viewed

\section{Emanuele Soricelli \\ Giovanni Casella \\ Giorgio Di Rocco \\ Adriano Redler \\ Nicola Basso}

Department of Surgical Sciences, Policlinico Umberto I, Sapienza, University of Rome, Italy
Correspondence: Nicola Basso Department of Surgical Sciences, Policlinico Umberto I, "Sapienza" University of Rome

Tel +39335647698I

Email nicola.basso@uniromal.it
Abstract: Since the early 2000s, laparoscopic sleeve gastrectomy has increasingly gained consensus in bariatric surgery, thanks to good to excellent results in terms of weight loss and comorbidity resolution, and to simpler technical aspects than in Roux-en-Y gastric bypass and biliopancreatic diversion. In yearly consensus summits, surgical indications, technical details, and management of complications, together with continuous update of data concerning clinical outcome, have been debated on the basis of increasing collective experience. In experimental studies and clinical trials, the pathophysiological mechanisms of weight loss and remission of cardiometabolic comorbidities subsequent to sleeve gastrectomy have been extensively discussed. The aim of this paper is to offer a review of state of the art laparoscopic sleeve gastrectomy and to focus attention on the currently most debated topics and future prospects of this procedure.

Keywords: sleeve gastrectomy, type 2 diabetes mellitus, gastroesophageal reflux disease, revisional, quality of life

\section{Introduction}

Sleeve gastrectomy (SG) was proposed and performed in 1988 by Hess and Hess ${ }^{1}$ as part of a hybrid malabsorptive procedure, the biliopancreatic diversion with duodenal switch (BPD-DS), because of the high incidence of marginal ulcers at the gastro-ileal anastomosis in the original Scopinaro biliopancreatic diversion (BPD) procedure. ${ }^{2}$ In the BPD conceived by Hess and Hess, ${ }^{1}$ an end-to-end suprapapillary duodeno-ileal anastomosis was combined with a vertical gastrectomy (SG) to achieve the gastric restriction required by Scopinaro BPD. In 1998, Marceau et al compared the clinical outcome of 252 patients undergoing BPD with 465 patients undergoing BDP-DS with a $100 \mathrm{~cm}$ long common channel (Scopinaro BPD: $50 \mathrm{~cm}$ ). ${ }^{3}$ The authors reported weight loss after BPD-DS greater than that after BPD, as well as a significant improvement in the malabsorption related side effects such as diarrhea, number of daily stools, vomiting, bone pain, and lack of serum vitamins and minerals.

In 2000, Ren et al demonstrated the feasibility of BPD-DS with a laparoscopic approach. ${ }^{4}$ Because of the high rate of complications and mortality in his early experience, he proposed a two stage laparoscopic BPD-DS: SG first and BPD-DS after an average 11 month interval. ${ }^{5}$ The results of the first step laparoscopic SG (LSG) were comparable with those of Roux-en-Y gastric bypass (RYGBP) in terms of weight loss and resolution of comorbidities. ${ }^{6}$ Thus, a growing number of surgeons were encouraged to perform LSG as a sole bariatric operation. In 2010, the American Society for Metabolic and Bariatric Surgery (ASMBS) issued a position statement recommending LSG as an approved bariatric procedure. ${ }^{7}$ 
In 2011, LSG became the second most performed bariatric operation after gastric bypass (27.8\% versus $46.6 \%)$, according to a survey of the International Federation for the Surgery of Obesity and Metabolic Disorders, with a five-fold increase when compared to data from a similar questionnaire in 2008. ${ }^{8,9}$

Since 2007 an International SG Summit Conference has been held every 2 years, allowing surgeons performing LSG to share clinical experiences and discuss technical aspects of the procedure. ${ }^{10-13}$ At the 2012 International SG Summit Conference, 130 surgeons reported on 46,133 procedures with a mean follow-up of 5 years. ${ }^{14}$

\section{Materials and methods}

The PubMed database was searched for citations that included LSG, using the keyword "sleeve gastrectomy" matched with the other heading terms of this paper, namely adolescents AND class I obesity AND leaks AND type 2 diabetes AND weight loss, etc. English language citations for human and animal studies reported from 1997 to December 2013 were included in the search. After an initial review of titles and abstracts, about 100 reports were analyzed and the full text reviewed when appropriate. Additional citations were obtained by manually reviewing the bibliographies of the reports selected for review.

\section{Surgical technique}

The laparoscopic surgical technique was first described and standardized by Ren et al. ${ }^{4}$ Under general anesthesia, the patient is positioned in reverse-Trendelenburg position, with legs abducted and the surgeon standing between the patient's legs. Four to six trocars are used. The procedure starts with the division of the vascular supply of the greater curvature of the stomach by means of ultrasonic or radiofrequency sealing devices. The division begins 4 to $6 \mathrm{~cm}$ from the pylorus and proceeds upwards until the gastric fundus and the angle of His are completely freed. If the dissection is too close to the pylorus, the antral pumping mechanism may be defective and the patient may experience nausea because of delayed emptying of the stomach. The most critical technical point is full mobilization of the gastric fundus after exposure of the left pillar of the diaphragm. These maneuvers will enable the surgeon to perform a complete fundectomy, the main precondition for a successful SG. To ascertain the occurrence of a hiatal hernia $(\mathrm{HH})$ there must be careful exploration of the hiatal area. The hiatal area can be approached from the right side on the lesser curvature, as in standard antireflux surgery, or from the left side after completing mobilization of the fundus. HH, when evidenced, should be repaired, either before or after transection of the stomach. ${ }^{15}$ Before transection, a bougie is inserted by the anesthesiologist down to the pylorus alongside the lesser curvature to calibrate the gastric tubule. The majority of surgeons use a $36 \mathrm{~F}$ bougie, although the range may vary from $32 \mathrm{~F}$ to $50 \mathrm{~F}$. Accurate placement of the bougie against the lesser curve of the stomach and stretching of the gastric walls by traction on the greater curve are of paramount importance to achieve a correct resection that will leave a residual gastric capacity of $60-80 \mathrm{~mL}$. LSG is performed using a linear stapler with closed height not less than $2.0 \mathrm{~mm}$ for the antrum (green cartridge) and not less than $1.5 \mathrm{~mm}$ (blue cartridge) for the fundus; when revisional surgery is performed, the use of $2.0 \mathrm{~mm}$ or higher cartridges may be advisable. The gastric transection begins 4 to $6 \mathrm{~cm}$ from the pylorus, while the last upper firing should stay 1-2 cm away from the esophagogastric junction to minimize the risk of leakage (Figure 1). ${ }^{16}$ To reduce the incidence of postoperative complications such as bleeding or leakage, $75 \%$ of surgeons routinely reinforce the staple line by means of buttressing materials or by oversewing with absorbable suture. ${ }^{14}$ At the end of the procedure, the staple line is usually tested by methylene blue or, more rarely, by intraoperative endoscopy. The gastric remnant can be extracted in a retrieval bag, using an "endo-loop" tightened at one extremity of the gastric specimen, or by simply retrieving the antral tip with a laparoscopic grasper through a slightly enlarged $12 \mathrm{~mm}$

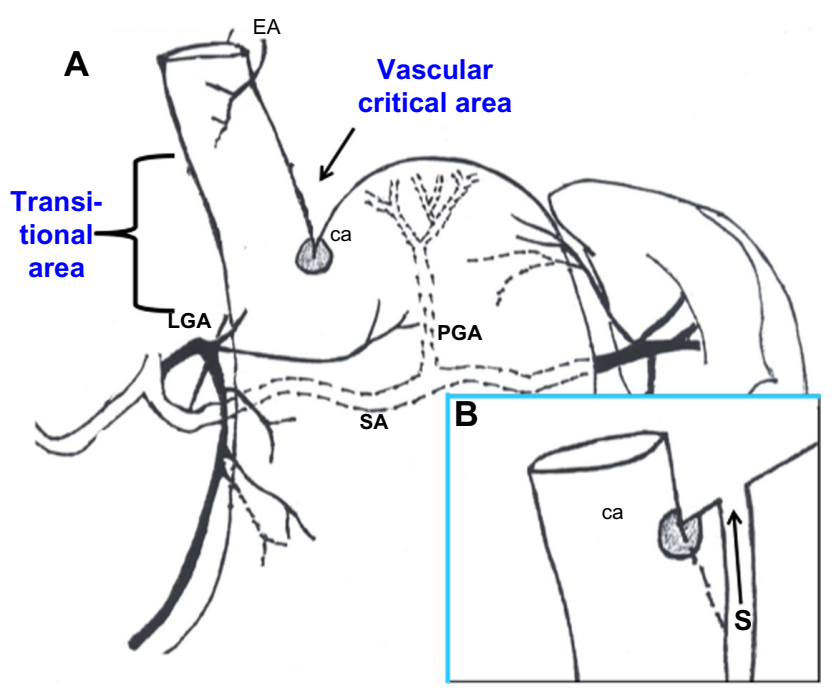

Figure I Gastric fundus vascularization.

Notes: (A) Vascular transitional area (critical area). The gastric fundus is vascularized by branches of the left gastric artery, the lower third of the esophagus by esophageal branches from the aorta. (B) "Safer" (S) line of section. Springer and Surg Endosc, 25, 20II, 444-449, Laparoscopic sleeve gastrectomy as first stage or definitive intent in 300 consecutive cases, Basso N, Casella G, Rizzello M, et al, Figure 4. ${ }^{16}$ With kind permission from Springer Science and Business Media.

Abbreviations: ca, critical area; EA, esophageal arteries; LGA, left gastric artery; PGA, posterior gastric artery; SA, splenic artery. 
trocar site. ${ }^{17}$ Postoperative upper gastrointestinal contrast study with water-soluble iodinated radiopaque contrast (Gastrografin $^{\circledR}$; Bracco Diagnostics Inc, Melville, NY, USA) may be performed 1 to 3 days after surgery.

\section{New surgical approaches}

\section{Single incision laparoscopic surgery (SILS)}

The application of SILS to bariatric surgery is quite recent. The first bariatric procedure to be reported using a single incision approach was the adjustable gastric banding in $2007,{ }^{18}$ while 2 years later the first case report of single incision transumbilical laparoscopic RYGBP was described. ${ }^{19}$ There has been growing literature on single incision transumbilical LSG since the first paper by Saber et al in $2008 .{ }^{20}$ However, even if published data are comparable with those of standard LSG in terms of operative time, weight loss, and incidence of postoperative complications, this approach still has limited application. ${ }^{21,22}$ This is because obesity enhances the technical challenges of SILS, such as loss of triangulation, conflicts between instruments inside and outside the abdomen, and lack of traction and counter traction. Moreover, the increased xypho-umbilical distance and enlarged liver could make access to the angle of His very difficult. The issues associated with the xypho-umbilical distance have been resolved with careful selection of patients and the application of longer instruments and flexible optics, while adequate liver retraction has been achieved with the addition of a subxiphoid trocar, ${ }^{23}$ retracting the left hepatic lobe to the anterior abdominal wall with a monofilament suture ${ }^{24}$ or by using the laparoscope itself as a retractor. ${ }^{25}$

\section{Natural orifice transluminal endoscopic surgery (NOTES)}

The initial clinical experience with human NOTES transvaginal SG was reported by Ramos et al in 2008. ${ }^{26}$ The authors described a hybrid approach entailing three abdominal trocars for establishment of pneumoperitoneum, dissection and stapling of the stomach, and one transvaginal trocar, which was used to introduce the laparoscope (or the flexible endoscope) and to retrieve the specimen at the end of the procedure. Mean operative time was 95 minutes, the postoperative course was uneventful, and all four patients enrolled in this study were discharged 2 days after surgery. The rationale of this approach is to further enhance the benefits of minimally invasive surgery by decreasing postoperative pain, lowering the incidence of wound related complications, and improving cosmetic results. There are still few papers dealing with LSG with the NOTES approach. ${ }^{27,28}$
Despite encouraging preliminary results, the application of this surgical procedure still requires critical analysis of the potential risks and disadvantages compared to a standard laparoscopic technique. Obviously the most important concerns of transvaginal access are the safety of this approach in terms of fertility, sexual function, and risk of infection. However, previous publications evaluating transvaginal appendectomy have shown that vaginal sensation, ability to reach orgasm, pregnancy, and childbirth are not affected by this approach. ${ }^{29,30}$

To reduce the incidence of trocar site complications related with the retrieval of such a large specimen as the resected stomach, the transgastric extraction of the specimen during LSG has been recently described by Dotai et al. ${ }^{31}$ The gastrectomy started about $5 \mathrm{~cm}$ nearer than in conventional LSG ( $8 \mathrm{~cm}$ from the pylorus). Once the gastrectomy is completed, a 2-3 cm gastrostomy is performed distal to the lower edge of the staple line allowing the endoscope to be guided into the peritoneal cavity under direct visualization. Then the specimen is tightened with an endoscopic snare and retrieved transorally through the gastric lumen. Finally, the defect on the stomach is closed by a laparoscopic stapler, starting $8 \mathrm{~cm}$ from the pylorus, and the relatively small resected specimen is extracted through one of the trocars. The authors compared the outcomes of 18 patients operated on submitted to LSG with transgastric specimen extraction with ten patients submitted to standard LSGs, finding no significant differences between the two groups except for increased specimen volume and reduced wound extension in the former.

\section{Robotics}

To date there are only a few published papers on the use of robots for LSG, describing some 200 cases with a similar outcome to that of the standard laparoscopic approach. ${ }^{32-37}$ As for other laparoscopic operations, robotic SG has certain advantages over the laparoscopic approach, including the ability of the robotic platform to reduce physical and cognitive stress during surgery, minimizing technical aspects, and resulting in faster and more accurate performance of laparoscopic tasks, such as suturing and dissection. In addition, the robotic system decreases the learning curve, allowing less skilled surgeons to safely perform the procedure. However, the costs of robotic SG are significantly higher than those of the standard laparoscopic procedure and there is still a lack of randomized trials demonstrating that the benefits of the robotic system can justify such an economic impact. ${ }^{38}$ 


\section{Indications}

Indications for LSG refer to those developed in 1991 by the National Institute of Health for all bariatric procedures. ${ }^{39}$ More recently, indications for surgery have been extended to categories of obese patients previously considered not amenable to surgical therapy.

\section{LSG in the elderly}

Advanced age has been considered in the past a relative contraindication to bariatric surgery due to increased postoperative risks and less weight reduction efficacy. The increasing incidence of obesity worldwide also entails a significant reduction in life expectancy in older people because of the development of weight related chronic comorbidities and disabilities. ${ }^{40}$ Thus, the potential health benefits of bariatric surgery in the elderly have been reconsidered. A significant body of literature shows that surgical management of obesity is not only safe, with morbidity and mortality rates comparable to those in the younger obese counterpart, but it can also provide long lasting effects in terms of associated disease resolution, quality of life (QoL) improvement, and longevity. ${ }^{41,42}$ Hazzan et al reported their experience on 55 patients with a mean age of 61.5 years (range $60-70$ years) operated on with RYGBP (60\%), gastric banding (16\%), BPD-DS (13\%), revisional surgery (5.5\%), and LSG $(5.5 \%) .{ }^{43}$ Of these, $49 \%$ had an American Society of Anesthesia score of 3 . The rate of conversion to open surgery and mortality within the first 30 days was nil, while the morbidity rate was $7.3 \%$. The authors concluded that bariatric surgery can be performed safely by experienced surgeons in the relatively more fragile subset of elderly patients, stressing the importance of careful selection of patients.

More recently, Soto et al retrospectively reviewed the clinical outcome in 35 patients (mean age, 66.3 years; range, 60-79 years) undergoing LSG. ${ }^{44}$ The overall morbidity rate was $8.4 \%$, lower than the rate reported $(19.5 \%)$ in a series of 92 RYGBP in elderly patients from the same center. Hypertension, type 2 diabetes mellitus (T2DM), obstructive sleep apnea (OSA), gastroesophageal reflux disease (GERD), and hyperlipidemia were resolved in $73 \%, 53 \%, 46 \%, 66 \%$, and $40 \%$ of cases, respectively.

\section{LSG in the pediatric/adolescent age}

As in the elderly population, the prevalence of obesity among children and adolescents is rapidly and dramatically increasing worldwide ${ }^{45}$ and it is associated with an increased risk of cardiovascular and metabolic diseases such as hypertension, T2DM, OSA, fatty liver disease, and cognitive deficits. ${ }^{46-48}$ Despite the proven efficacy of bariatric surgery in adult patients, surgical management of obese children or adolescents is still a matter of debate. The most important concerns are related to the psychological implications of complex surgical interventions in this age group and to the lack of knowledge about long-term metabolic and growth consequences. ${ }^{49}$

Literature data favor weight loss procedures in carefully selected, extremely obese adolescents..$^{50}$ The improvement in obesity related comorbidities after bariatric surgery supports the concept of "early" intervention in this group of patients. ${ }^{51,52}$ At present, laparoscopic adjustable gastric banding (LAGB) and RYGBP are the most commonly performed bariatric procedures, with encouraging results in terms of safety and efficacy. ${ }^{53,54}$ However, there is insufficient evidence for singling out or recommending specific bariatric procedures. ${ }^{55}$

Published data on LSG in the pediatric/adolescent age are fewer than those after RYGBP and LAGB due to the novelty of the procedure, but the clinical outcome seems to be promising. Boza et al reported on 51 patients aged $<19$ years undergoing LSG. ${ }^{56}$ Two years after surgery, excess weight loss (EWL) was $92.9 \%$ and the rate of resolution of hypertension and T2DM was $100 \%$ and $50 \%$, respectively. The QoL after surgery, investigated by the Moorehead-Ardelt questionnaire, ${ }^{57}$ was described as "very good" in $60 \%$ of patients and "good" in $40 \%$ of patients. Likewise, Alqahtani et al reported on LSG performed on 108 obese adolescents aged 5 to 21 years $^{58}$ where no major postoperative complications occurred. At a 24 month follow-up, results were remarkable in terms of EWL (62.3\%), and hypertension, OSA, and T2DM remission (75.0\%, 90.9\%, and $93.8 \%$, respectively). Similar data reported by Nadler et al confirmed the feasibility and effectiveness of LSG in morbidly obese adolescent patients, suggesting a reconsideration of bariatric surgery in this group of patients. ${ }^{59}$ To evaluate persistence of weight loss and maturation to adulthood, long-term and numerically more consistent data are needed.

\section{Class I obesity (body mass index [BMI] $30-35 \mathrm{~kg} / \mathrm{m}^{2}$ )}

Increasing evidence suggests that an augmented risk for developing weight related diseases such as T2DM, cardiovascular diseases, and cancers is present in class I obesity patients. ${ }^{60}$ In several randomized controlled trials (RCTs), nonsurgical management (namely diet programs, exercise, drug therapy, and behavioral therapy) of obese patients with BMI $30-35 \mathrm{~kg} / \mathrm{m}^{2}$ was not effective in achieving a substantial 
and durable weight loss. ${ }^{61,62}$ On the other hand, a number of published RCTs or observational studies support the hypothesis that in patients with $\mathrm{BMI}<35 \mathrm{~kg} / \mathrm{m}^{2}$, bariatric procedures provide an outcome in terms of weight loss, longterm QoL, health care costs, and resolution of comorbidities comparable to that of morbidly obese patients. ${ }^{63,64} \mathrm{~T} 2 \mathrm{DM}$ significantly improved after surgery, ${ }^{65-67}$ with a significant reduction in cardiovascular medications when compared to the nonsurgical approach. ${ }^{68}$

In an RCT by Schauer et al, 150 obese patients with poorly controlled T2DM (mean $\mathrm{HbA}_{1 \mathrm{c}}$ [mean glycated hemoglobin] of $9.2 \%$ ) were randomly assigned to receive intensive medical therapy (IMT) or IMT plus RYGBP or IMT plus LSG. ${ }^{69}$ Thirty-four percent of these patients had a BMI $<35 \mathrm{~kg} / \mathrm{m}^{2}$. At a 1 year follow-up the clinical results in the surgical groups were significantly better in terms of glycemic control and weight loss. In another study, 18 nonmorbidly obese diabetic patients were randomized into two groups receiving LSG or medical therapy. In the LSG group, T2DM remitted in eight of nine patients and improved in one. No diabetes mellitus (DM) remission was observed in the medical therapy group, confirming that LSG may be a promising tool in the surgical armamentarium for T2DM therapy, even in nonmorbidly obese patients. ${ }^{68}$

\section{Revisional surgery}

After primary bariatric procedures, up to $56 \%$ of cases require surgical revision because of unsatisfactory weight loss or weight regain, intolerable adverse effects, mechanical complications, and severe metabolic or nutritional complications. ${ }^{70-73}$ Revisional bariatric surgery is complex and technically demanding with augmented risk for postoperative complications. ${ }^{74-76}$

Adjustable gastric banding and vertical banded gastroplasty are the procedures more frequently requiring surgical revision, with an incidence higher than $50 \%$ of cases in some series. ${ }^{77-79}$ Although laparoscopic RYGBP is considered by most surgeons the procedure of choice to revise failed restrictive procedures ${ }^{80,81}$ recently LSG has been reported as a feasible and effective revisional procedure to address surgery in these patients. ${ }^{82,83}$ The rationale is related to current knowledge that SG works not only because of a restrictive mechanism, but also through hormonal factors unrelated to restriction. ${ }^{84}$ In a recent review, Coblijn et al collected 286 revisional LSGs for failed gastric banding from eight papers. ${ }^{85}$ The indications for surgery were insufficient weight loss or weight regain $(63.9 \%)$, band slippage, and food intolerance with vomiting ( $14.7 \%$ and $9.4 \%$, respectively).
Band removal and LSG were performed in one step in $63.4 \%$ of cases and in two steps in the remaining cases. The rate of postoperative complications was $12.2 \%$; staple line leak had an incidence of $5.6 \%$, higher than that reported in primary SG patients. EWL after revisional LSG (follow-up 13-36 months) ranged from $16.7 \%$ to $64.2 \%$. In our unpublished experience, the two step strategy was adopted only in cases in which a band related complication such as pouch dilation or gastric wall erosion (19\%) was present. All these data support the growing confidence in LSG in the management of failed primary restrictive bariatric procedure.

\section{Liver cirrhosis}

A final note must address the indications for patients with liver cirrhosis. This condition may be difficult to diagnosis preoperatively, especially in extreme- or super-obese patients for whom a malabsorptive procedure is indicated. Intraoperatively, when this unexpected situation occurs LSG may offer a valid alternative because of its lack of malabsorptive components and the valid EWL effects. ${ }^{86,87}$

\section{Complications}

LSG is a safe procedure. The postoperative mortality rate varies from $0.1 \%$ to $0.5 \%$ and the postoperative morbidity rate ranges from $0.0 \%$ to $12 \%$. Early diagnosis is the most important factor to ensure a positive solution. Operative treatment is required only in selected cases. ${ }^{14}$ The main complications include hemorrhage, gastric leak, stenosis, and gastroesophageal reflux disease.

\section{Hemorrhage}

Hemorrhage (1\%-2\%) usually occurs within the first 24-48 hours. Almost always the bleeding is into the abdominal cavity because it originates from the line of the gastric resection or from the gastroepiploic vessels divided to mobilize the stomach. The treatment is interventional radiology, or in fewer instances, open or laparoscopic surgical exploration. ${ }^{87}$ Suture line reinforcement has significantly reduced the occurrence of this complication. ${ }^{88-91}$

\section{Gastric leak}

Gastric leak $(0 \%-7 \%)$ is the most feared complication. It should be always hypothesized when the normal postoperative course alters. Acute leaks can occur within 7 days postoperatively, or early leaks can occur within 1-6 weeks; later leaks occur less frequently. In $90 \%$ of cases, leaks occur at the upper portion of the gastric suture line and a vascular factor in the genesis of this complication has been 
suggested (Figure 1). ${ }^{16}$ The treatment consists of drainage of the abdominal collection by interventional radiology, antibiotics, and parenteral nutrition. Endoscopic stenting may be of use. ${ }^{92-95}$ Surgery is indicated in uncontained leaks, symptomatic with signs of general infection and hemodynamic instability. At this time, attempts to repair the leak should be avoided. Surgical repair of the fistula is indicated in the rare instances of chronic ( $>12-16$ weeks) fistulas. ${ }^{13,96}$

\section{Stenosis}

Stenosis $(0.6 \%)$ usually occurs at the corpus-antrum transition zone (incisura angularis) of the gastric tubule. RYGBP reconstruction after failed conservative stricture treatment is a valid therapy. ${ }^{13,97}$

\section{GERD}

The relation between LSG and GERD is still a matter for discussion. Some investigators reported the development or worsening of GERD symptoms after LSG and for this reason they consider the preoperative diagnosis of GERD and/or HH as a contraindication to LSG. ${ }^{11}$ In their opinion, the gastric transection performed near the angle of His may play an adverse role on the effectiveness of the lower esophageal sphincter owing to the partial section of the sling fibers and/or the marked increase of intragastric pressure after LSG. ${ }^{98,99}$ Other authors reported an improvement of GERD symptoms after LSG. ${ }^{15,100}$ The late dilation of the gastric remnant with decreased intragastric pressure, the acceleration of gastric emptying, and the reduction of acid secretion have been considered to play a beneficial role in the improvement of GERD symptoms after SG. ${ }^{101}$

In the presence of $\mathrm{HH}$, the indication to perform crural closure in addition to SG is still debated. Most investigators perform RYGBP, rather than $\mathrm{LSG}$, with $\mathrm{HH}$ repair (HHR) if a crural defect is diagnosed preoperatively. ${ }^{11}$ Recently, the clinical outcome in 97 patients operated on for LSG plus HHR was compared to that of 281 patients undergoing LSG alone. ${ }^{15}$ The data of this study showed: 1) high incidence of intraoperative $\mathrm{HH}$ (not previously ascertained) diagnosis after accurate hiatal region exploration; 2) effective management of GERD symptoms with a remission rate of $80 \%$ after hiatoplasty; and 3 ) no cases of postoperative GERD symptom onset in patients without symptomatic reflux before surgery. The authors suggest that an undetected and untreated $\mathrm{HH}$ could favor the genesis of postoperative GERD symptoms. Vigorous efforts to diagnose and treat HH were recommended.

\section{Outcome \\ Weight loss}

The effect of LSG on weight loss has been favorably compared to that of intensive medical therapy in randomized and in prospective trials. ${ }^{102}$ As reported in the ASMBS updated position statement and in other randomized trials, LSG can determine weight loss comparable to that after RYGBP, ${ }^{6,103-106}$ while it is more effective than LAGB. ${ }^{103,107,108}$ At the beginning its effectiveness was attributed solely to a restrictive action. Melissas et al and Dimitriadis et al demonstrated that the reduction of energy intake after LSG was achieved through significant neurohormonal changes: gastric fundectomy caused a significant decrease in the circulating levels of ghrelin, the hormone of appetite, while the rapid gastric emptying entailed a food mediated release of glucagon-like peptide-1 (GLP-1) and peptide-YY (PYY) from the L cells of the small intestine. These changes persisted 1 year after surgery, showing that LSG can be considered a "food limiting" operation rather than a restrictive procedure. ${ }^{109,110}$

Concerning the long-term outcome of this procedure, during the Third International Summit on Sleeve Gastrectomy $^{12}$ data from more than 19,000 LSGs were collected. Mean percentages of EWL after 1, 2, 3, 4, and 5 years were $62.7 \%, 64.7 \%, 64.0 \%, 57.3 \%$, and $60.0 \%$ respectively. These results have been confirmed in the Fourth Consensus: the mean EWL in more than 46,000 LSGs was 50\% at the 6 year follow-up. ${ }^{14} \mathrm{~A}$ comparable outcome in smaller study populations has been reported by Himpens et al. ${ }^{111}$ The longest follow-up was reported by Sarela et al: 8 to 9 years after LSG, 13 patients had an EWL of $68 \% .{ }^{112}$

Long-term weight regain remains a controversial and largely insufficiently documented issue. As a secondary procedure for weight regain, resleeve in $20 \%$, RYGBP conversion in $46 \%$, and duodenal switch in $24 \%$ of cases have been chosen. ${ }^{14}$

\section{Effect on comorbidities}

In 2006 we reported on the effectiveness of $\mathrm{SG}$ on comorbidities in super-obese patients. ${ }^{113}$ At an 18 month follow-up, arterial hypertension, OSA, and T2DM resolved in $62.5 \%, 56.2 \%$, and $76.9 \%$ of cases, respectively, and improved in the majority of the remaining cases. In the ASMBS 2009 position statement, ${ }^{7}$ data from ten studies ( $n=754$ patients) on the evolution of comorbidities after LSG were analyzed. T2DM remission ranged from $14 \%$ to $100 \%$, arterial hypertension from $15 \%$ to $93 \%$, and OSA from $39 \%$ to $100 \%$. 


\section{T2DM}

In several studies it has been shown that $60 \%-80 \%$ of diabetic obese patients undergoing LSG achieve a complete remission of their pathology. ${ }^{114-117}$ These results compared very favorably to those obtained after an intensive medical regimen ${ }^{102}$ and were not statistically different from those after RYGBP. ${ }^{118,119}$ Experimental and clinical studies involving LSG have been of paramount importance in understanding how this surgical procedure can improve glycemic homeostasis. Karamanakos et al showed a significant increase in both fasting and postprandial PYY plasma levels and a marked reduction in fasting ghrelin plasma levels after SG. ${ }^{120}$ PYY improves insulin resistance, while ghrelin acts by suppressing the insulin-sensitizing hormone adiponectin, blocking hepatic insulin signaling and inhibiting insulin secretion. ${ }^{121}$ GLP-1, both in vivo and in vitro, stimulates insulin biosynthesis in pancreatic beta-cells. ${ }^{122,123}$ In addition to its insulinotropic effects, GLP-1 exerts glucose lowering effects through inhibition of gastric emptying, restoration of insulin sensitivity, and inhibition of glucagon secretion, resulting in decreased hepatic glucose production. ${ }^{123}$ Peterli et al analyzed fasting and meal stimulated GLP-1, PYY, and ghrelin modifications after RYGBP and SG. ${ }^{124}$ One week after completion of both procedures, basal and meal stimulated plasma levels of GLP-1 and PYY were significantly augmented. Fasting ghrelin plasma levels were significantly diminished after both procedures.

When nutrients are ingested, the release of GLP-1 (cosecreted with PYY) into the circulation occurs in a biphasic manner, consisting of a rapid (10-15 minutes) early phase followed by a more prolonged (30-60 minutes) second phase. ${ }^{125}$ The latter phase is explained by the direct stimulation of the $\mathrm{L}$ cells from digested nutrients subsequent to the rapid food passage through the distal small bowel, as postulated by Rubino in the "hindgut hypothesis." 126 Several studies in both animal and human models on the former phase have demonstrated that ingestion of the nutrients activates a neuroendocrine pathway which stimulates the secretion of $\mathrm{L}$ cells before any passage of ingested food into the distal small bowel. ${ }^{127-129}$ This early activation of the $\mathrm{L}$ cells is mediated from the vagus nerve through the release of both acetylcholine and gastrin-releasing peptide within the enteric nervous system. ${ }^{130}$ Consistent with these findings, subsequent studies have shown that bilateral subdiaphragmatic vagotomy prevents stimulation of rat $\mathrm{L}$ cells by duodenal fat, while direct activation of the celiac branch of the vagus increases secretion. ${ }^{131,132}$

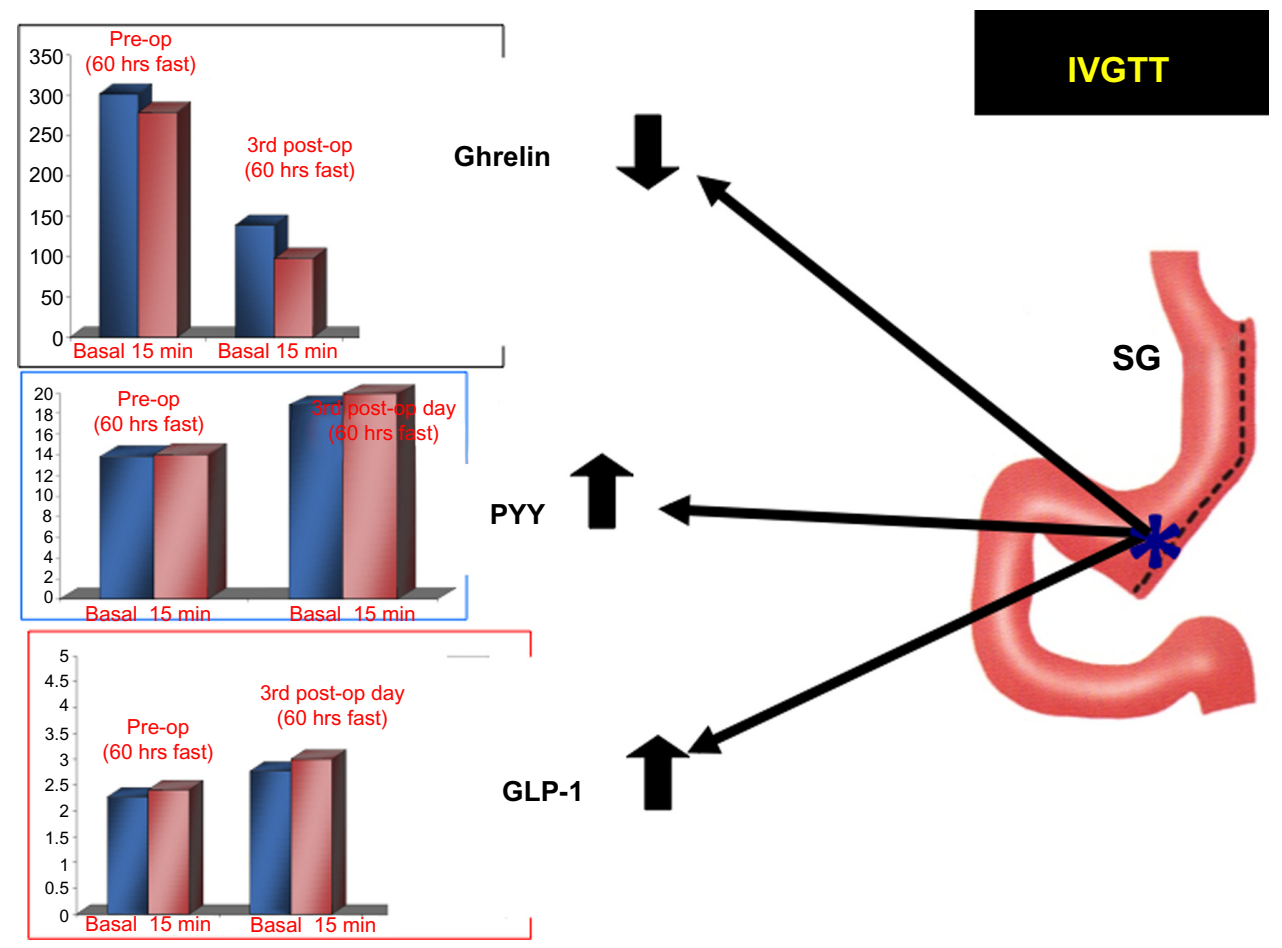

Figure 2 Pre- and post-operative laparoscopic sleeve gastrectomy glucagon-like peptide-I, ghrelin, and peptide-YY plasma levels in the basal state and I5 minutes after intravenous glucose tolerance test.

Note: The changes are not related to weight loss or to nutrient stimulation of the small intestine.

Abbreviations: GLP-I, glucagon-like peptide-I; PYY, peptide-YY; SG, sleeve gastrectomy; min, minutes; hrs, hours; op, operative; IVGTT, intravenous glucose tolerance test. 
In 2011 we investigated the changes in insulin secretion and sensitivity after LSG in 18 diabetic obese patients. ${ }^{133}$ Both these parameters improved significantly just 72 hours after the intervention, before any weight loss or food passage through the alimentary tract had occurred. Concomitantly, early modifications in plasma levels of ghrelin, PYY, and GLP-1 were observed (Figure 2). As the postoperative plasma levels of these peptides were tested before the ingestion of any food, the nutrient mediated (both early and late) stimulation of the L cells may be conceivably ruled out. Thus, an intrinsic neurohormonal effect of the procedure was suggested, stressing the role of the gastric resection per se as the pathogenic factor. A "gastric hypothesis" was formulated, postulating that the diminished hydrochloric acid production induced by the significant reduction of oxyntic cell mass stimulates the vagally innervated antral mucosa, left intact by SG, to secret gastrinreleasing peptide and, as a consequence, GLP-1 (Figure 3). Moreover, in this study, modifications of ghrelin, PYY, and GLP-1 appeared to be statistically significant in the group of patients with a diabetes duration $<10.5$ years, but not in the group of patients with T2DM duration $>10.5$ years.

The role of disease duration as a major predictor of DM remission induced by $\mathrm{SG}$ has been confirmed in another study by our group. ${ }^{135} \mathrm{DM}$ remission occurred in $100 \%$ of patients with DM duration $<10$ years and in only $31 \%$ of patients when the duration was $>10$ years. ${ }^{135}$ Two additional factors have been considered of value in predicting T2DM

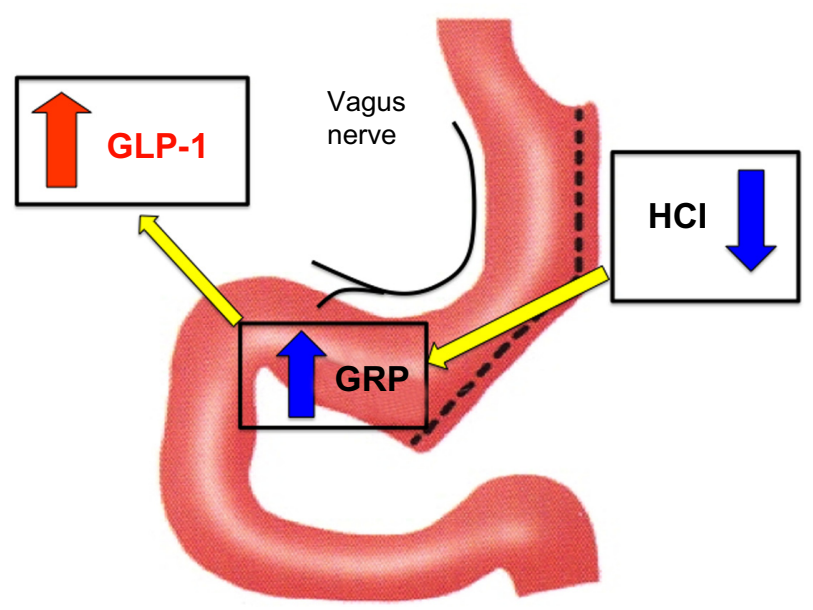

Figure 3 The "gastric hypothesis."

Notes: Decreased hydrochloric acid production consequent to laparoscopic sleeve gastrectomy may act on the innervated antrum to produce gastrin-releasing peptide responsible for glucagon-like peptide-I (GLP-I) early phase secretion, while the second phase is dependent on direct contact of nutrients on the $L$ cells of the ileum. ${ }^{134}$ Springer and Surg Endosc, 25, 20I I, 3540-3550, First-phase insulin secretion, insulin sensitivity, ghrelin, GLP-I, and PYY changes $72 \mathrm{~h}$ after sleeve gastrectomy in obese diabetic patients: the gastric hypothesis, Basso N, Capoccia D, Rizzello M, et al, Figure 10. ${ }^{133}$ With kind permission from Springer Science and Business Media. Abbreviations: GRP, gastrin-releasing peptide; $\mathrm{HCl}$, hydrochloric acid. remission after surgery: preoperative levels of C-peptide above $3 \mathrm{ng} / \mathrm{mL}$ and preoperative insulin therapy when present. ${ }^{136}$ When analyzing the long-term antidiabetic effect of LSG, remission was present in $87.8 \%$ of patients at a followup of 60 months. ${ }^{137}$ In these patients a significant reduction of the Framingham cardiac risk score was also observed. Remodeling of left ventricular hypertrophy, detected in patients 1.5 years after $\mathrm{SG}$, is in accord with this finding. ${ }^{138}$

\section{Patient satisfaction}

Traditionally, bariatric surgery results have been evaluated on the basis of weight loss and comorbidity resolution. However, these factors are not the only or the most important criteria to be considered for a successful outcome. Patient satisfaction is of utmost importance in the correct evaluation of the results. Improved QoL and enhanced psychosocial functioning are important goals for bariatric surgery and should be actively pursued and evaluated. A crucial requirement for achieving patient satisfaction is a comprehensive and exhaustive informed consent. The patient must be fully aware of the effects and possible side effects of the procedure and, most important, postoperative expectations must be realistic to avoid disappointment and depression.

Several papers report encouraging results on the topic of QoL after LSG. D'Hondt et $\mathrm{al}^{139}$ analyzed the QoL in 83 LSG patients, using Medical Outcomes Survey Short Form 36 and Bariatric Analysis and Reporting Outcome System (BAROS) $)^{140}$ questionnaires, and determined the food tolerance score. ${ }^{141}$ The BAROS score was "good" to "excellent" in $90 \%$ of patients at a 6 year follow-up, while the food tolerance was acceptable to excellent in $95.2 \%$ of patients. In Short Form 36, "physical functioning" and "general health perception" only had scores significantly better in patients with EWL > 50\% than in patients with EWL $<50 \%$, suggesting that weight loss is not the only factor influencing the results. Alley et al ${ }^{142}$ retrospectively reviewed the outcome in 108 patients (69 LSG and 39 LAGB), administering a validated QoL questionnaire (Bariatric Quality of Life). ${ }^{143}$ After a mean follow-up of 9.3 months, the QoL score was higher in the LSG group than in the LAGB group. Over time patients demonstrated a clear preference for SG once it was offered.

\section{Conclusion}

In a very short period of time SG has become an extremely popular bariatric procedure both among patients and surgeons. There are many reasons for this "sleeve explosion": 1) technically it is not a very difficult operation although as already outlined, strict adherence to crucial 
technical details is critical to obtain good functional results; 2) morbidity and mortality are low even in extreme and highly extreme obese patients; 3 ) there is no residual "blind stomach" as in RYGBP; 4) there are no foreign bodies as in gastric banding; 5) there is no nutrient malabsorption with related side effects and no need for nutrient supplementation as in BPD; 6) the feasibility of postoperative endoscopic exploration of the biliary tree is maintained; and 7) the treatment of failures is well standardized (ie, second stage, RYGBP, or resleeve).

Because of its novelty, the full extent of LSG effects remains to be explored since not all the mechanisms for its actions on weight, DM, cardiopathy, etc, have been thoroughly clarified. For the same reasons, long-term (10 years or more) results are still not available. Nevertheless LSG is already an established and reliable procedure in the bariatric field and a very promising asset for future developments in the therapy of twenty-first century "globesity."

\section{Disclosure}

The authors have no commercial associations that might entail a conflict of interest in relation to this article.

\section{References}

1. Hess DS, Hess DW. Biliopancreatic diversion with a duodenal switch. Obes Surg. 1998;8(3):267-282.

2. Scopinaro N, Gianetta E, Pandolfo N, Anfossi A, Berretti B, Bachi V. [Bilio-pancreatic bypass. Proposal and preliminary experimental study of a new type of operation for the functional surgical treatment of obesity]. Minerva Chir. 1976;31(10):560-566. Italian.

3. Marceau P, Hould FS, Simard S, et al. Biliopancreatic diversion with duodenal switch. World J Surg. 1998;22(9):947-954.

4. Ren CJ, Patterson E, Gagner M. Early results of laparoscopic biliopancreatic diversion with duodenal switch: a case series of 40 consecutive patients. Obes Surg. 2000;10(6):514-523.

5. Regan JP, Inabnet WB, Gagner M, Pomp A. Early experience with two-stage laparoscopic Roux-en-Y gastric bypass as an alternative in the super-super obese patient. Obes Surg. 2003;13(6):861-864.

6. Boza C, Gamboa C, Salinas J, Achurra P, Vega A, Pérez G. Laparoscopic Roux-en-Y gastric bypass versus laparoscopic sleeve gastrectomy: a case-control study and 3 years of follow-up. Surg Obes Relat Dis. 2012;8(3):243-249.

7. Clinical Issues Committee of the American Society for Metabolic and Bariatric Surgery. Updated position statement on sleeve gastrectomy as a bariatric procedure. Surg Obes Relat Dis. 2010;6(1):1-5.

8. Buchwald H, Oien DM. Metabolic/bariatric surgery Worldwide 2008. Obes Surg. 2009;19(12):1605-1611.

9. Buchwald H, Oien DM. Metabolic/bariatric surgery worldwide 2011. Obes Surg. 2013;23(4):427-436.

10. Deitel M, Crosby RD, Gagner M. The First International Consensus Summit for Sleeve Gastrectomy (SG), New York City, October 25-27, 2007. Obes Surg. 2008;18(5):487-496.

11. Gagner M, Deitel M, Kalberer TL, Erickson AL, Crosby RD. The Second International Consensus Summit for Sleeve Gastrectomy, March 19-21, 2009. Surg Obes Relat Dis. 2009;5(4):476-485.

12. Deitel M, Gagner M, Erickson AL, Crosby RD. Third International Summit: Current status of sleeve gastrectomy. Surg Obes Relat Dis. 2011;7(6):749-759.
13. Rosenthal RJ; International Sleeve Gastrectomy Expert Panel, Diaz AA, et al. International Sleeve Gastrectomy Expert Panel Consensus Statement: best practice guidelines based on experience of $>12,000$ cases. Surg Obes Relat Dis. 2012;8(1):8-19.

14. Gagner M, Deitel M, Erickson AL, Crosby RD. Survey on laparoscopic sleeve gastrectomy (LSG) at the Fourth International Consensus Summit on Sleeve Gastrectomy. Obes Surg. 2013;23(12):2013-2017.

15. Soricelli E, Iossa A, Casella G, Abbatini F, Calì B, Basso N. Sleeve gastrectomy and crural repair in obese patients with gastroesophageal reflux disease and/or hiatal hernia. Surg Obes Relat Dis. 2013;9(3): 356-361.

16. Basso N, Casella G, Rizzello M, et al. Laparoscopic sleeve gastrectomy as first stage or definitive intent in 300 consecutive cases. Surg Endosc. 2011;25(2):444-449.

17. Casella G, Soricelli E, Fantini A, Basso N. A time-saving technique for specimen extraction in sleeve gastrectomy. World J Surg. 2010;34(4): 765-767.

18. Teixeira J, McGill K, Koshy N, McGinty J, Todd G. Laparoscopic single-site surgery for placement of adjustable gastric band - a series of 22 cases. Surg Obes Relat Dis. 2010;6:41-45.

19. Huang CK, Houng JY, Chiang CJ, Chen YS, Lee PH. Single incision transumbilical laparoscopic Roux-en-Y gastric bypass: a first case report. Obes Surg. 2009;19(12):1711-1715.

20. Saber AA, Elgamal MH, Itawi EA, Rao JA. Single incision laparoscopic sleeve gastrectomy (SILS): a novel technique. Obes Surg. 2008;18(10): $1338-1342$.

21. Reavis KM, Hinojosa MW, Smith BR, Nguyen NT. Single-laparoscopic incision transabdominal surgery sleeve gastrectomy. Obes Surg. 2008;18(11):1492-1494.

22. Mittermair R, Pratschke J, Sucher R. Single-incision laparoscopic sleeve gastrectomy. Am Surg. 2013;79(4):393-397.

23. Saber AA, El-Ghazaly TH. Feasibility of single-access laparoscopic sleeve gastrectomy in super-super obese patients. Surg Innov. 2010;17(1):36-40.

24. Lakdawala MA, Muda NH, Goel S, Bhasker A. Single-incision sleeve gastrectomy versus conventional laparoscopic sleeve gastrectomy - a randomised pilot study. Obes Surg. 2011;21(11):1664-1670.

25. Gentileschi P, Camperchioli I, Benavoli D, Di Lorenzo N, Sica G, Gaspari AL. Laparoscopic single-port sleeve gastrectomy for morbid obesity: preliminary series. Surg Obes Relat Dis. 2010;6:65-69.

26. Ramos AC, Zundel N, Neto MG, Maalouf M. Human hybrid NOTES transvaginal sleeve gastrectomy: initial experience. Surg Obes Relat Dis. 2008;4:660-663.

27. Horgan S, Meireles OR, Jacobsen GR, et al. Broad clinical utilization of NOTES: is it safe? Surg Endosc. 2013;27(6):1872-1880.

28. Lacy AM, Delgado S, Rojas OA, Ibarzabal A, Fernandez-Esparrach G, Taura P. Hybrid vaginal MA-NOS sleeve gastrectomy: technical note on the procedure in a patient. Surg Endosc. 2009;23(5): $1130-1137$.

29. Mofid H, Emmermann A, Alm M, von Waldenfels HA, Felixmuller C, Zornig C. Is the transvaginal route appropriate for intra-abdominal NOTES procedures? Experience and follow-up of 222 cases. Surg Endosc. 2013;27:2807-2812.

30. Peterson CY, Ramamoorthy S, Andrews B, Horgan S, Talamini M, Chock A. Women's positive perception of transvaginal NOTES surgery. Surg Endosc. 2009;23:1770-1774.

31. Dotai T, Coker AM, Antozzi L, et al. Transgastric large-organ extraction: the initial human experience. Surg Endosc. 2013;27(2):394-399.

32. Diamantis T, Alexandrou A, Nikiteas N, Giannopoulos A, Papalambros E. Initial experience with robotic sleeve gastrectomy for morbid obesity. Obes Surg. 2011;21(8):1172-1179.

33. Ayloo S, Buchs NC, Addeo P, Bianco FM, Giulianotti PC. Robotassisted sleeve gastrectomy for super-morbidly obese patients. J Laparoendosc Adv Surg Tech A. 2011;21(4):295-299.

34. Abdalla RZ, Garcia RB, Luca CR, Costa RI, Cozer Cde O. Brazilian experience in obesity surgery robot-assisted. Arq Bras Cir Dig. 2012;25(1):33-35. 
35. Elli EF, Masrur MA, Giulianotti PC. Robotic sleeve gastrectomy after liver transplantation. Surg Obes Relat Dis. 2013;9(1):e20-e22.

36. Vilallonga R, Fort JM, Gonzalez O, et al. The initial learning curve for robot-assisted sleeve gastrectomy: a surgeon's experience while introducing the robotic technology in a bariatric surgery department. Minim Invasive Surg. 2012;2012:347131.

37. Romero RJ, Kosanovic R, Rabaza JR, et al. Robotic sleeve gastrectomy: experience of 134 cases and comparison with a systematic review of the laparoscopic approach. Obes Surg. 2013;23:1743-1752.

38. Cirocchi R, Boselli C, Santoro A, et al. Current status of robotic bariatric surgery: a systematic review. BMC Surg. 2013;13(1):53.

39. NIH conference. Gastrointestinal surgery for severe obesity. Consensus Development Conference Panel. Ann Intern Med. 1991; 115(12):956-961.

40. Elia M. Obesity in the elderly. Obes Res. 2001;9 Suppl 4:244S-248S.

41. Dorman RB, Abraham AA, Al-Refaie WB, Parsons HM, Ikramuddin S, Habermann EB. Bariatric surgery outcomes in the elderly: an ACS NSQIP study. J Gastrointest Surg. 2012;16(1):35-44.

42. Varela JE, Wilson SE, Nguyen NT. Outcomes of bariatric surgery in the elderly. Am Surg. 2006;72(10):865-869.

43. Hazzan D, Chin EH, Steinhagen E, et al. Laparoscopic bariatric surgery can be safe for treatment of morbid obesity in patients older than 60 years. Surg Obes Relat Dis. 2006;2(6):613-616.

44. Soto FC, Gari V, de la Garza JR, Szomstein S, Rosenthal RJ. Sleeve gastrectomy in the elderly: a safe and effective procedure with minimal morbidity and mortality. Obes Surg. 2013;23(9):1445-1449.

45. Weiss R. Bariatric surgery for obese adolescents - "make assurance doubly sure." Obes Facts. 2009;2:277-280.

46. Dietz WH, Robinson TN. Clinical practice: overweight children and adolescent. $N$ Engl J Med. 2005;352:2100-2109.

47. Dileepan K, Feldt MM. Type 2 diabetes mellitus in children and adolescents. Pediatr Rev. 2013;34(12):541-548.

48. Zhang Z, Kris-Etherton PM, Hartman TJ. Birth weight and risk factors for cardiovascular disease and type 2 diabetes in us children and adolescents: 10 year results from NHANES. Matern Child Health J. Epub November 16, 2013.

49. Iqbal CW, Kumar S, Iqbal AD, Ishitani MB. Perspectives on pediatric bariatric surgery: identifying barriers to referral. Surg Obes Relat Dis. 2009;5:88-93.

50. Inge TH, Zeller MH, Lawson L, Daniels SR. Critical appraisal of the evidence supporting bariatric surgery for weight management in adolescence. $J$ Pediatr. 2005;147:10-19.

51. Garcia VF, DeMaria EJ. Adolescent bariatric surgery: treatment delayed, treatment denied, a crisis invited. Obes Surg. 2006;16:1-4.

52. Inge TH. Bariatric surgery for morbidly obese adolescents: is there a rationale for early intervention? Growth Horm IGF Res. 2006; 16(Suppl A):S15-S19.

53. Pratt JS, Lenders CM, Dionne EA, et al. Best practice updates for pediatric/ adolescent weight loss surgery. Obes (Silver Spring). 2009;17: 901-910.

54. Treadwell JR, Sun F, Schoelles K. Systematic review and metaanalysis of bariatric surgery for pediatric obesity. Ann Surg. 2008;248: 763-776.

55. Michalsky M, Reichard K, Inge T, Pratt J, Lenders C; American Society for Metabolic and Bariatric Surgery. ASMBS pediatric committee best practice guidelines. Surg Obes Relat Dis. 2012;8(1):1-7.

56. Boza C, Viscido G, Salinas J, Crovari F, Funke R, Perez G. Laparoscopic sleeve gastrectomy in obese adolescents: results in 51 patients. Surg Obes Relat Dis. 2012;8(2):133-137.

57. Moorehead MK, Ardelt-Gattinger E, Lechner H, Oria HE. The validation of the Moorehead-Ardelt Quality of Life Questionnaire II. Obes Surg. 2003;13(5):684-692.

58. Alqahtani AR, Antonisamy B, Alamri H, Elahmedi M, Zimmerman VA. Laparoscopic sleeve gastrectomy in 108 obese children and adolescents aged 5 to 21 years. Ann Surg. 2012;256(2):266-273.

59. Nadler EP, Barefoot LC, Qureshi FG. Early results after laparoscopic sleeve gastrectomy in adolescents with morbid obesity. Surgery. 2012;152(2):212-217.
60. Guh DP, Zhang W, Bansback N, Amarsi Z, Birmingham CL, Anis AH. The incidence of co-morbidities related to obesity and over-weight: a systematic review and meta-analysis. BMC Public Health. 2009;9:88.

61. Avenell A, Brown TJ, McGee MA, et al. What interventions should we add to weight reducing diets in adults with obesity? A systematic review of randomized controlled trials of adding drug therapy, exercise, behaviour therapy or combinations of these interventions. J Hum Nutr Diet. 2004;17:293-316.

62. Padwal R, Li SK, Lau DC. Long-term pharmacotherapy for overweight and obesity: a systematic review and meta-analysis of randomized controlled trials. Int J Obes Relat Metab Disord. 2003;27: $1437-1446$

63. ASMBS Clinical Issues Committee. Bariatric surgery in class I obesity (body mass index 30-35 kg/m²). Surg Obes Relat Dis. 2013;9(1): e1-e10.

64. Keating CL, Dixon JB, Moodie ML, et al. Cost-effectiveness of surgically induced weight loss for the management of type 2 diabetes: modeled lifetime analysis. Diabetes Care. 2009;32:567-574.

65. Dixon JB, O'Brien PE, Playfair J, et al. Adjustable gastric banding and conventional therapy for type 2 diabetes: a randomized controlled trial. JAMA. 2008;299:316-323.

66. Cohen R, Pinheiro JC, Schiavon CA, Salles JE, Wajchenberg BL, Cummings DE. Effects of gastric bypass surgery in patients with type 2 diabetes and only mild obesity. Diabetes Care. 2012;35: $1420-1428$.

67. Lee WJ, Chong K, Ser KH, et al. Gastric bypass vs sleeve gastrectomy for type 2 diabetes mellitus: a randomized controlled trial. Arch Surg. 2011;146:143-148.

68. Abbatini F, Capoccia D, Casella G, Coccia F, Leonetti F, Basso N. Type 2 diabetes in obese patients with body mass index of $30-35 \mathrm{~kg} / \mathrm{m}^{2}$ : sleeve gastrectomy versus medical treatment. Surg Obes Relat Dis. 2012;8:20-24

69. Schauer PR, Kashyap SR, Wolski K, et al. Bariatric surgery versus intensive medical therapy in obese patients with diabetes. $N$ Engl $J$ Med. 2012;366:1567-1576.

70. Kellogg TA. Revisional bariatric surgery. Surg Clin N Am. 2011;91: 1353-1371.

71. Buckwalter JA, Herbst CA Jr, Khouri RK. Morbid obesity. Second gastric operations for poor weight loss. Am Surg. 1985;51:208-211.

72. Nesset EM, Kendrick ML, Houghton SG, et al. A two-decade spectrum of revisional bariatric surgery at a tertiary referral center. Surg Obes Relat Dis. 2007;3(1):25-30.

73. Spyropoulos C, Kehagias I, Panagiotopoulos S, Mead N, Kalfarentzos F. Revisional bariatric surgery: 13-year experience from a tertiary institution. Arch Surg. 2010;145:173-177.

74. Brolin RE, Cody RP. Weight loss outcome of revisional bariatric operations varies according to the primary procedure. Ann Surg. 2008;248: 227-232.

75. Cohen R, Pinheiro JS, Correa JL, Schiavon C. Laparoscopic revisional bariatric surgery: myths and facts. Surg Endosc. 2005;19:822-825.

76. Gagner M, Gentileschi P, de Csepel J, et al. Laparoscopic reoperative bariatric surgery: experience from 27 consecutive patients. Obes Surg. 2002;12:254-260

77. Gazala SA, Keidar A. Conversion of failed gastric banding into four different bariatric procedures. Surg Obes Relat Dis. 2012;8:400-407.

78. Muller MK, Attigah N, Wildi S, et al. High secondary failure rate of rebanding after failed gastric banding. Surg Endosc. 2007;22: $448-453$.

79. van Gemert WG, van Wersch MM, Greve JW, Soeters PB. Revisional surgery after vertical banded gastroplasty: restoration of vertical banded gastroplasty or conversion to gastric bypass. Obes Surg. 1998;8: 21-28.

80. Weber M, Müller MK, Michel JM, et al. Laparoscopic Roux-en-Y gastric bypass, but not rebanding, should be proposed as rescue procedure for patients with failed laparoscopic gastric banding. Ann Surg. 2003;238:827-834. 
81. Iannelli A, Amato D, Addeo P, et al. Laparoscopic conversion of vertical banded gastroplasty (Mason MacLean) into Roux-en-Y gastric bypass. Obes Surg. 2008;18:43-46.

82. Foletto M, Prevedello L, Bernante P, et al. Sleeve gastrectomy as revisional procedure for failed gastric banding or gastroplasty. Surg Obes Relat Dis. 2010;6(2):146-151.

83. Dapri G, Cadière GB, Himpens J. Feasibility and technique of laparoscopic conversion of adjustable gastric banding to sleeve gastrectomy. Surg Obes Relat Dis. 2009;5:72-76.

84. Iannelli A, Schneck AS, Ragot E, et al. Laparoscopic sleeve gastrectomy as revisional procedure for failed gastric banding and vertical banded gastroplasty. Obes Surg. 2009;19(9):1216-1220.

85. Coblijn UK, Verveld CJ, van Wagensveld BA, Lagarde SM. Laparoscopic Roux-en-Y gastric bypass or laparoscopic sleeve gastrectomy as revisional procedure after adjustable gastric band: a systematic review. Obes Surg. 2013;23(11):1899-1914.

86. Shimizu H, Phuong V, Maia M, et al. Bariatric surgery in patients with liver cirrhosis. Surg Obes Relat Dis. 2013;9(1):1-6.

87. Takata MC, Campos GM, Ciovica R, et al. Laparoscopic bariatric surgery improves candidacy in morbidly obese patients awaiting transplantation. Surg Obes Relat Dis. 2008;4(2):159-164.

88. Silecchia G, Rizzello M, Casella G, Fioriti M, Soricelli E, Basso N. Twostage laparoscopic biliopancreatic diversion with duodenal switch as treatment of high-risk super-obese patients: analysis of complications. Surg Endosc. 2009;23(5):1032-1037.

89. Choi YY, Bae J, Hur KY, Choi D, Kim YJ. Reinforcing the staple line during laparoscopic sleeve gastrectomy: does it have advantages? A meta-analysis. Obes Surg. 2012;22(8):1206-1213.

90. Dapri G, Cadière GB, Himpens J. Reinforcing the staple line during laparoscopic sleeve gastrectomy: prospective randomized clinical study comparing three different techniques. Obes Surg. 2010;20(4): 462-467.

91. Macias CA, Sandler B, Barajas-Gamboa JS, et al. Standardized protocol utilization decreases rate of complications: a study of laparoscopic sleeve gastrectomy in 189 consecutive patients. Surg Endosc. 2013;27:S489.

92. Stamou KM, Menenakos E, Dardamanis D, et al. Prospective comparative study of the efficacy of staple-line reinforcement in laparoscopic sleeve gastrectomy. Surg Endosc. 2011;25(11): 3526-3530.

93. Almadi MA, Aljebreen AM, Bamihriz F. Resolution of an esophageal leak and posterior gastric wall necrosis with esophageal self-expandable metal stents. World J Gastroenterol. 2013;19(40): 6931-6933.

94. Simon F, Siciliano I, Gillet A, Castel B, Coffin B, Msika S. Gastric leak after laparoscopic sleeve gastrectomy: early covered self-expandable stent reduces healing time. Obes Surg. 2013;23(5):687-692.

95. Fischer A, Bausch D, Richter-Schrag HJ. Use of a specially designed partially covered self-expandable metal stent (PSEMS) with a 40-mm diameter for the treatment of upper gastrointestinal suture or staple line leaks in 11 cases. Surg Endosc. 2013;27(2):642-647.

96. Casella G, Soricelli E, Rizzello M, et al. Nonsurgical treatment of staple line leaks after laparoscopic sleeve gastrectomy. Obes Surg. 2009;19(7):821-826.

97. Parikh A, Alley JB, Peterson RM, et al. Management options for symptomatic stenosis after laparoscopic vertical sleeve gastrectomy in the morbidly obese. Surg Endosc. 2012;26(3):738-746.

98. Braghetto I, Lanzarini E, Korn O, Valladares H, Molina JC, HenriquezA. Manometric changes of the lower esophageal sphincter after sleeve gastrectomy in obese patients. Obes Surg. 2010;20:357-362.

99. Braghetto I, Csendes A, Korn O, Valladares H, Gonzalez P, HenríquezA. Gastroesophageal reflux disease after sleeve gastrectomy. Surg Laparosc Endosc Percutan Tech. 2010;20:148-155.

100. Chiu S, Birch DW, Shi X, Sharma AM, Karmali S. Effect of sleeve gastrectomy on gastroesophageal reflux disease: a systematic review. Surg Obes Relat Dis. 2011;7:510-515.
101. Pomerri F, Foletto M, Allegro G, Bernante P, Prevedello L, Muzzio PC. Laparoscopic sleeve gastrectomy - radiological assessment of fundus size and sleeve voiding. Obes Surg. 2011;21:858-863.

102. Leonetti F, Capoccia D, Coccia F, et al. Obesity, type 2 diabetes mellitus, and other comorbidities: a prospective cohort study of laparoscopic sleeve gastrectomy vs medical treatment. Arch Surg. 2012; 147(8):694-700.

103. ASMBS Clinical Issues Committee. Updated position statement on sleeve gastrectomy as a bariatric procedure. Surg Obes Relat Dis. 2012;8(3):e21-e26.

104. Vidal P, Ramón JM, Goday A, et al. Laparoscopic gastric bypass versus laparoscopic sleeve gastrectomy as a definitive surgical procedure for morbid obesity. Mid-term results. Obes Surg. 2013;23(3):292-299.

105. Kehagias I, Karamanakos SN, Argentou M, Kalfarentzos F. Randomized clinical trial of laparoscopic Roux-en-Y gastric bypass versus laparoscopic sleeve gastrectomy for the management of patients with BMI $<50 \mathrm{~kg} / \mathrm{m}^{2}$. Obes Surg. 2011;21(11):1650-1656.

106. Chouillard EK, Karaa A, Elkhoury M, Greco VJ; Intercontinental Society of Natural Orifice, Endoscopic, and Laparoscopic Surgery (i-NOELS). Laparoscopic Roux-en-Y gastric bypass versus laparoscopic sleeve gastrectomy for morbid obesity: case-control study. Surg Obes Relat Dis. 2011;7(4):500-505.

107. Varela JE. Laparoscopic sleeve gastrectomy versus laparoscopic adjustable gastric banding for the treatment severe obesity in high risk patients. JSLS. 2011;15(4):486-491.

108. Himpens J, Dapri G, Cadière GB. A prospective randomized study between laparoscopic gastric banding and laparoscopic isolated sleeve gastrectomy: results after 1 and 3 years. Obes Surg. 2006;16(11): 1450-1456.

109. Melissas J, Daskalakis M, Koukouraki S, et al. Sleeve gastrectomy-a "food limiting" operation. Obes Surg. 2008;18(10):1251-1256.

110. Dimitriadis E, Daskalakis M, Kampa M, Peppe A, Papadakis JA, Melissas J. Alterations in gut hormones after laparoscopic sleeve gastrectomy: a prospective clinical and laboratory investigational study. Ann Surg. 2013;257(4):647-654.

111. Himpens J, Dobbeleir J, Peeters G. Long-term results of laparoscopic sleeve gastrectomy for obesity. Ann Surg. 2010;252:319-324.

112. Sarela AI, Dexter SP, O'Kane M, Menon A, McMahon MJ. Long-term follow-up after laparoscopic sleeve gastrectomy: 8-9-year results. Surg Obes Relat Dis. 2012;8(6):679-684.

113. Silecchia G, Boru C, Pecchia A, et al. Effectiveness of laparoscopic sleeve gastrectomy (first stage of biliopancreatic diversion with duodenal switch) on co-morbidities in super-obese high-risk patients. Obes Surg. 2006;16(9):1138-1144.

114. Abbatini F, Rizzello M, Casella G, et al. Long-term effects of laparoscopic sleeve gastrectomy, gastric bypass, and adjustable gastric banding on type 2 diabetes. Surg Endosc. 2010;24(5):1005-1010.

115. Cottam D, Qureshi FG, Mattar SG, et al. Laparoscopic sleeve gastrectomy as an initial weight-loss procedure for high-risk patients with morbid obesity. Surg Endosc. 2006;20(6):859-863.

116. Vidal J, Ibarzabal A, Romero F, et al. Type 2 diabetes mellitus and the metabolic syndrome following sleeve gastrectomy in severely obese subjects. Obes Surg. 2008;18(9):1077-1082.

117. Cheverie J, Jacobsen GR, Sandler BJ, et al. Laparoscopic sleeve gastrectomy: an efficacious management of metabolic syndrome in the morbidly obese. Surg Endosc. 2013;27:S254.

118. Schauer PR, Burguera B, Ikramuddin S, et al. Effect of laparoscopic Roux-en Y gastric bypass on type 2 diabetes mellitus. Ann Surg. 2003;238(4):467-484.

119. Buchwald H, Avidor Y, Braunwald E, et al. Bariatric surgery: a systematic review and meta-analysis. JAMA. 2004;292(14):1724-1737.

120. Karamanakos SN, Vagenas K, Kalfarentzos F, Alexandrides TK. Weight loss, appetite suppression, and changes in fasting and postprandial ghrelin and peptide-YY levels after Roux-en-Y gastric bypass and sleeve gastrectomy: a prospective, double blind study. Ann Surg. 2008;247(3):401-407. 
121. Vestergaard ET, Djurhuus CB, Gjedsted J, et al. Acute effects of ghrelin administration on glucose and lipid metabolism. J Clin Endocrinol Metab. 2008;93(2):438-444.

122. Meier JJ, Gallwitz B, Salmen S, et al. Normalization of glucose concentrations and deceleration of gastric emptying after solid meals during intravenous glucagon-like peptide 1 in patients with type 2 diabetes. J Clin Endocrinol Metab. 2003;88(6):2719-2725.

123. Kindel TL, Yoder SM, Seeley RJ, D’Alessio DA, Tso P. Duodenal-jejunal exclusion improves glucose tolerance in the diabetic, Goto-Kakizaki rat by a GLP-1 receptor-mediated mechanism. J Gastrointest Surg. 2009;13(10):1762-1772.

124. Peterli R, Wölnerhanssen B, Peters T, et al. Improvement in glucose metabolism after bariatric surgery: comparison of laparoscopic Roux-en-Y gastric bypass and laparoscopic sleeve gastrectomy: a prospective randomized trial. Ann Surg. 2009;250(2):234-241.

125. Konturek SJ, Pepera J, Zabielski K, et al. Brain-gut axis in pancreatic secretion and appetite control. J Physiol Pharmacol. 2003;54(3): 293-317.

126. Rubino F. Is type 2 diabetes an operable intestinal disease? A provocative yet reasonable hypothesis. Diabetes Care. 2008;31 Suppl 2: S290-S296.

127. Brubaker PL, Anini Y. Direct and indirect mechanisms regulating secretion of glucagon-like peptide-1 and glucagon-like peptide-2. Can J Physiol Pharmacol. 2003;81(11):1005-1012.

128. Greeley GH, Jeng YJ, Gomez G, et al. Evidence for regulation of peptide-YY release by the proximal gut. Endocrinology. 1989;124: 1438-1443.

129. Fu-Cheng X, Anini Y, Chariot J, Castex C, Galmiche JP, Rozé C. Mechanisms of peptide YY release induced by an intraduodenal meal in rats: neural regulation by proximal gut. Pflugers Arch. 1997;433: 571-579.

130. Reimer RA, Darimont C, Gremlich S, Nicolas-Metral V, Ruegg UT, Mace K. A human cellular model for studying the regulation of glucagon-like peptide-1 secretion. Endocrinology. 2001;142: 4522-4528.

131. Rocca AS, Brubaker PL. Role of the vagus nerve in mediating proximal nutrient-induced glucagon-like peptide-1 secretion. Endocrinology. 1999;140:1687-1694.

132. Balks HJ, Holst JJ, Von zur Mühlen A, Brabant G. Rapid oscillations in plasma glucagon-like peptide-1 (GLP-1) in humans: Cholinergic control of GLP-1 secretion via muscarinic receptors. J Clin Endocrinol Metab. 1997;82:786-790.
133. Basso N, Capoccia D, Rizzello M, et al. First-phase insulin secretion, insulin sensitivity, ghrelin, GLP-1, and PYY changes $72 \mathrm{~h}$ after sleeve gastrectomy in obese diabetic patients: the gastric hypothesis. Surg Endosc. 2011;25(11):3540-3550.

134. Perez-Tilve D, Nogueiras R, Mallo F, Benoit SC, Tschoep M. Gut hormones ghrelin, PYY, and GLP-1 in the regulation of energy balance (corrected) and metabolism. Endocrine. 2006;29(1):61-71.

135. Casella G, Abbatini F, Calì B, Capoccia D, Leonetti F, Basso N. Tenyear duration of type 2 diabetes as prognostic factor for remission after sleeve gastrectomy. Surg Obes Relat Dis. 2011;7(6):697-702.

136. Lee WJ, Ser KH, Chong K, et al. Laparoscopic sleeve gastrectomy for diabetes treatment in nonmorbidly obese patients: efficacy and change of insulin secretion. Surgery. 2010;147(5):664-669.

137. Abbatini F, Capoccia D, Casella G, Soricelli E, Leonetti F, Basso N. Long-term remission of type 2 diabetes in morbidly obese patients after sleeve gastrectomy. Surg Obes Relat Dis. 2013;9(4):498-502.

138. Cavarretta E, Casella G, Calì B, et al. Cardiac remodeling in obese patients after laparoscopic sleeve gastrectomy. World J Surg. 2013;37(3):565-572.

139. D'Hondt M, Vanneste S, Pottel H, Devriendt D, Van Rooy F, Vansteenkiste F. Laparoscopic sleeve gastrectomy as a single-stage procedure for the treatment of morbid obesity and the resulting quality of life, resolution of comorbidities, food tolerance, and 6-year weight loss. Surg Endosc. 2011;25(8):2498-2504.

140. Oria HE, Moorehead MK. Bariatric Analysis and Reporting Outcome System (BAROS). Obes Surg. 1988;8:487-499.

141. Suter M, Calmes JM, Paroz A, Giusti V. A new questionnaire for quick assessment of food tolerance after bariatric surgery. Obes Surg. 2007;17(1):2-8.

142. Alley JB, Fenton SJ, Harnisch MC, Tapper DN, Pfluke JM, Peterson RM. Quality of life after sleeve gastrectomy and adjustable gastric banding. Surg Obes Relat Dis. 2012;8(1):31-40.

143. Weiner S, Sauerland S, Fein M, Blanco R, Pomhoff I, Weiner R. The bariatric quality of life (BQL) index: a measure of well-being in obesity surgery patients. Obes Surg. 2005;15:538-545.
Open Access Surgery

\section{Publish your work in this journal}

Open Access Surgery is an international, peer-reviewed, open access journal that focuses on all aspects of surgical procedures and interventions. Patient care around the peri-operative period and patient outcomes post surgery are key topics. All grades of surgery from minor cosmetic interventions to major surgical procedures are covered. Novel techniques

\section{Dovepress}

and the utilization of new instruments and materials, including implants and prostheses that optimize outcomes constitute major areas of interest. The manuscript management system is completely online and includes a very quick and fair peer-review system. Visit http://www.dovepress.com/ testimonials.php to read real quotes from published authors. 